CASE REPORTS

\title{
CONTINUOUS VENOUS HUM IN A CASE OF PORTAL CIRRHOSIS \\ BY
}

\author{
A. I. S. MACPHERSON AND E. V. B. MORTON
}

\section{From the Department of Surgery and the Department of Medicine, University of Edinburgh}

Venous hums to be heard on auscultation over the epigastrium in cases of portal cirrhosis were described more than a hundred years ago by Pégot (1833) and by Cruveilhier (1835), and early in this century by Baumgarten (1908). Hanganutz (1922) collected six cases all of which presented a small cirrhotic liver, portal hypertension, a venous anastomosis in the falciform ligament and abdominal wall connecting the portal and the epigastric veins and a bruit or hum audible over the epigastrium and lower end of the sternum. He believed this syndrome to be a separate clinical and pathological entity and applied to it the name Cruveilhier-Baumgarten cirrhosis. Armstrong et al. (1942) reviewed the cases published to that date and divided them into two groups. The first consisted of young people in whom there was atrophy of the parenchyma of the liver, but little or no fibrosis, and a large patent vein which joined the left portal vein to the abdominal parietal veins by way of the free margin of the falciform ligament. Armstrong and his colleagues believed that this was the umbilical vein and that its congenital patency was the primary abnormality in these cases, the changes in the liver being secondary to the deprivation of portal blood. They considered these cases to be examples of Cruveilhier-Baumgarten cirrhosis. In the second and much larger group, which they referred to as the Cruveilhier-Baumgarten syndrome, no congenital anomaly was present. The primary condition was hepatic cirrhosis with associated portal hypertension. Partial recanalization of the obliterated umbilical vein occurred in some patients and in others enlargement of the para-umbilical veins (Sappey, 1889) and of the connections between them and the epigastric veins. Two further instances have since been described by Bloom (1950).

In normal development the umbilical vein is obliterated a few days after birth, but its connection with the left branch of the portal vein and its proximal (hepatic) end frequently remain patent. According to Segall (1923) it was patent for variable distances up to two-thirds of its length in 19 of the 55 specimens he examined. This "Restkanal" (Baumgarten) may in turn communicate with the epigastric veins through the small veins of Burow (1838). The anastomosis is of no significance in the healthy individual, but assumes importance as part of the collateral circulation should portal hypertension develop. In describing three cases seen at necropsy Butler (1952) indicated that this form of portal-epigastric anastomosis varied greatly in size, in one instance the lumen of the replacing vein being so large that it could only be distinguished from a congenitally patent umbilical vein by the histological structure of its wall.

The following case is presented as an example of the Cruveilhier-Baumgarten syndrome in which the cirrhosis and portal-epigastric anastomosis were associated with gross ascites. A venous hum was heard in the epigastrium and was recorded with the phonocardiograph.

\section{Case Report}

A single woman, aged 73, was admitted to the charge of Dr. W. I. Card in the Western General Hospital, Edinburgh, with a short history of weakness, dyspnea on exertion, ankle swelling, and loss of weight. Most of the patient's life had been spent in the Dutch West Indies, where she had always been healthy. A small consumption of alcohol was admitted. In 1948 chronic cholecystitis was diagnosed on the basis of mild dyspepsia and a non-functioning gall-bladder. There was no history of other illness. 
Physical Examination. Temperature and pulse and respiration rates were normal. The patient was very thin. Although there was no jaundice, the skin was dry and pigmented, and showed a widespread psoriasis. The hands presented "liver palm" appearance, but no finger clubbing. Apart from mental confusion, no abnormality of the central nervous system could be detected. There were scanty basal crepitations, but no venous congestion or peripheral œdema, and in other respects the cardiovascular system was normal. A moderate ascites was present and the liver edge was just palpable. On auscultation over the epigastrium and lower sternum, a curious humming bruit could be heard. Rectal examination revealed only the presence of small hæmorrhoids.

Laboratory Findings. Urine contained a trace of urobilinogen but no bile or other abnormality. Fæces were normal in appearance; no occult blood was detected. Blood: Hb. 94 per cent, W.B.C. 4,000 per c.mm., E.S.R. $45 \mathrm{~mm}$./hr.; plasma proteins, total 6.75 g. per $100 \mathrm{ml}$. (albumin, 3.20, globulin 3.55); serum bilirubin $0.9 \mathrm{mg}$. per $100 \mathrm{ml}$; ; alkaline phosphatase 16 units (King); cephalin cholesterol flocculation $+(4)$; blood urea nitrogen $12 \mathrm{mg}$. per $100 \mathrm{ml}$. Electrocardiogram normal. There was a histamine-fast achlorhydria. X-rays of the chest showed no abnormality; films of the abdomen (erect) showed moderate distension of the bowel with several fluid levels and evident ascites; barium swallow revealed extensive œsophageal varices.

Progress. On the third day after admission the patient lapsed into a coma which lasted four days. She made a complete recovery and over the succeeding four months showed no tendency to relapse, but the ascites increased and gross peripheral œdema appeared. Paracentesis abdominis was performed on nine occasions with a total withdrawal of 40 litres of fluid. Repeated injections of mercurial diuretics were given with varying but never very good response. High protein diet with oral hepovite and supplementary vitamins was not well tolerated. There was a low grade intermittent fever and the patient complained of occasional right-sided abdominal pain, which was relieved by analgesic tablets. Five months after admission her condition began to deteriorate, progressive weakness and muscle wasting developed and the response to mercurial diuretics became progressively smaller. For three weeks before death she was comatose and took no food or drink. She died in a state of gross inanition with massive ascites and peripheral œdema.

The Murmur. The murmur was heard on auscultation over the epigastrium, the medial third of both costal margins and over the sternum as far up as the third costal cartilage. It was maximal on either side of the xiphoid cartilage, was heard in all phases of respiration and did not vary with posture. It resembled the murmur of a patent ductus arteriosus in that it was continuous throughout systole and diastole, and varied slightly in intensity and pitch with the cardiac cycle. In character the murmur was a soft-pitched hum not unlike the noise of wind blowing through telegraph wires, and conformed to the original description of a venous hum given by Laennec (1819), who likened it to the sound of the " sea or that produced by the application of a large shell to the ear." There was no palpable thrill. Although no large subcutaneous

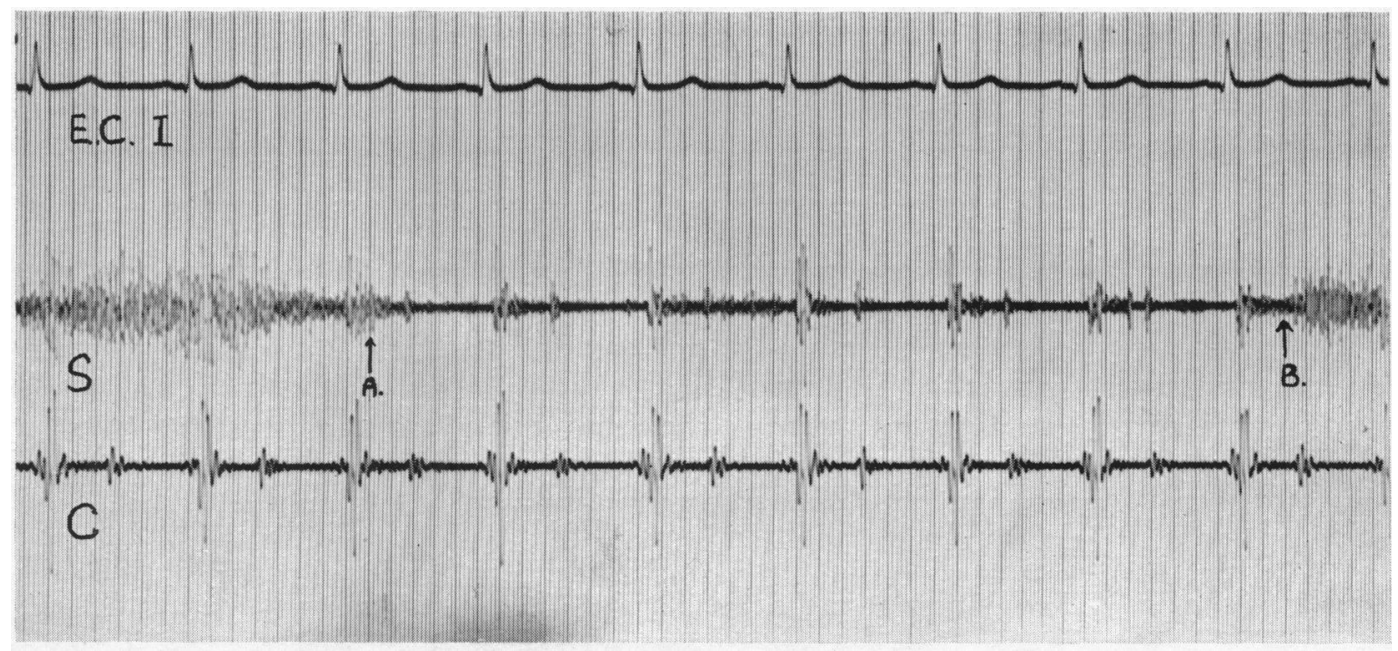

FIG. 1.-Continuous venous hum in hepatic cirrhosis. Simultaneous recordings of electrocardiogram (lead I) and phonocardiograms at lower end of sternum (S) and at cardiac apex (C); (A) light pressure applied with hand on epigastrium; (B) pressure released. 
veins were visible above the umbilicus the murmur disappeared when light digital pressure was applied across the epigastrium in the mid-line and reappeared immediately pressure was released.

Two synchronous phonocardiograms were recorded (Fig. 1), one from a point just over the lower end of the sternum where the murmur was loudest and a second simultaneous tracing from the cardiac apex to show the normal heart sounds. At the point on the tracing marked "A " gentle pressure applied with the edge of the hand across the epigastrium caused the murmur to disappear. When pressure was released, at the point " $B$ " on the tracing, the murmur reappeared.

A series of vibrations can be seen to persist in the sternal tracing when pressure was applied. The regular vibrations coincide with the normal heart sounds as recorded at the apex and are in fact the heart sounds which are conducted from the præcordium and only become apparent in the epigastrium when the venous hum is obliterated. The irregular high frequency vibrations represent the breath sounds, the patient being unable to breathe quietly or hold her breath while the recording was being made.

Necropsy showed the presence of gross hepatic cirrhosis. The gall-bladder contained a single mixed stone with a cholesterol nucleus and was the seat of suppurative cholecystitis with localized abscess formation. There was a massive ascites and œdema of all the connective tissue spaces. The heart was normal and the lungs were congested. The microscopical appearance of the liver showed extensive fibrosis and complete replacement of the normal lobular architecture by areas of nodular hyperplasia.

The venous anastomosis was demonstrated after death by injection into the superior mesenteric vein of a solution of 1 per cent methylene blue and 12 per cent potassium iodide. A drawing of the dissected specimen is shown in Fig. 2. The round ligament was unusually large and was so stained by the methylene blue that in the naked-eye specimen it seemed that complete recanalization must have occurred. Only the hepatic end of the umbilical vein was in fact patent. As it entered the free edge of the falciform ligament the single lumen disappeared and its place was taken by innumerable small channels in and around the round ligament which in other respects showed a normal adult structure. From this portion of the round ligament one moderate sized and several small veins communicated with a dilated and tortuous vein which ran cephalad in the extra-peritoneal tissues. At the distal (umbilical) end of the round ligament there were,

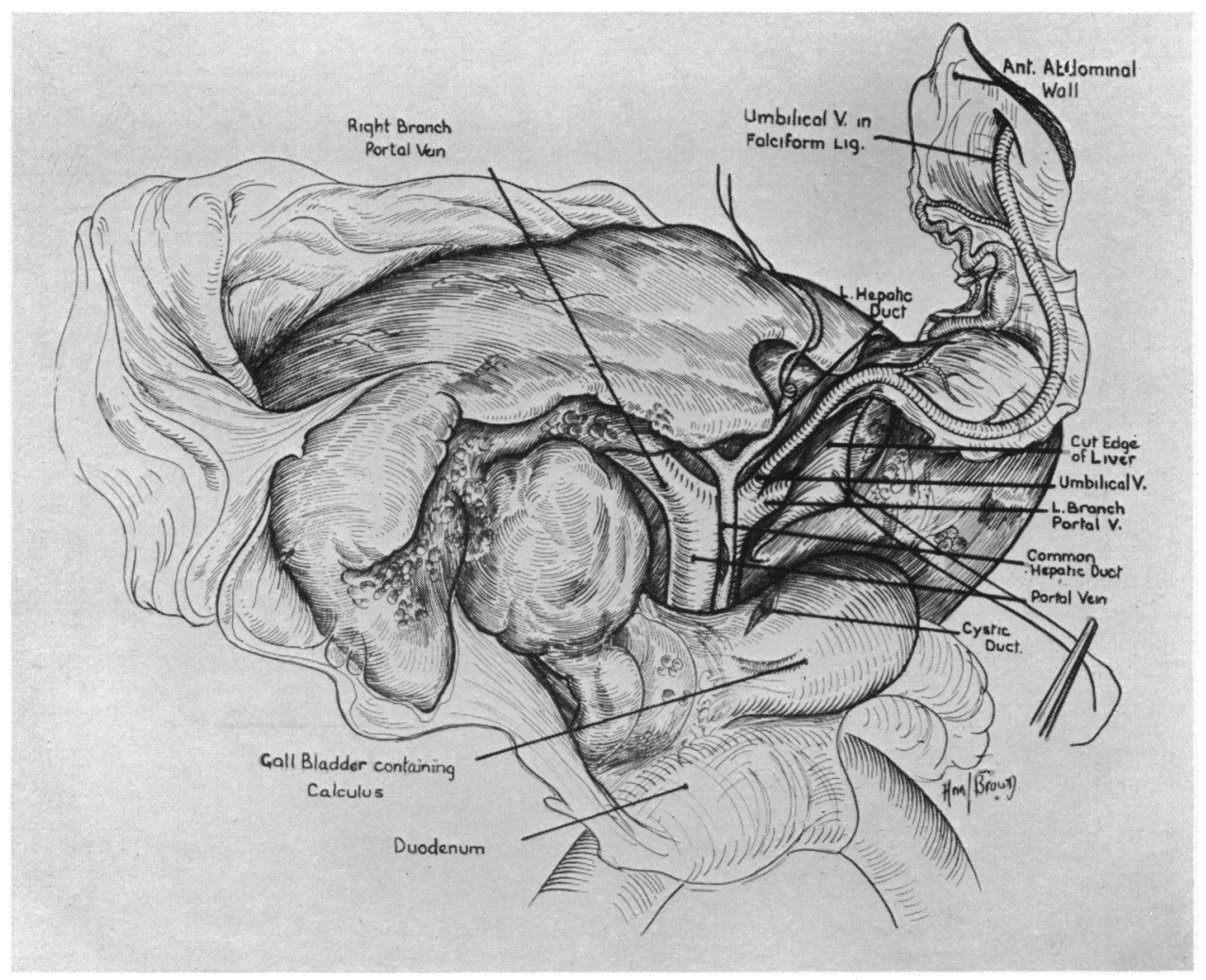

FIG. 2.-Drawing of the specimen removed at necropsy to show the portal-epigastric anastomosis along the falciform ligament. 
in addition to the para-umbilical veins, small vessels within the ligament approximately $0.5 \mathrm{~mm}$. in diameter and with relatively thick walls, which consisted largely of fibrous tissue. A lateral radiograph demonstrated that the opaque medium had traversed the portal-epigastric anastomosis observed in the necropsy specimen and had entered the internal mammary veins in the retro-sternal plane.

\section{Discussion}

Portal-systemic venous connections in portal hypertension have been classified as (1) dangerous or vulnerable, and (2) protected or beneficial anastomoses (McNee and Macpherson, 1952; Butler, 1952). The first group comprises the varices at the lower end of the œsophagus and in the fundus of the stomach which by reason of their exposed position are liable to rupture and to give rise to the hæmorrhages which are characteristic of this condition. The second group includes the retroperitoneal anastomoses, enlargement of intra-muscular and intra-neural vessels (such as those described by Butler (1952) within the vagus sheaths) and the veins in the hepatic and falciform ligaments. The presence of these connections is entirely beneficial, but for the most part they are of such small calibre that it takes many thousands of them to compensate for the obstruction to flow through one large vessel. A postero-anterior radiograph demonstrated this point in the present case, showing that the portal-epigastric anastomosis was of small size and of little practical importance in comparison with the collateral circulation which had developed in relation to the left gastric vein.

It is not possible to determine exactly the site of origin of the murmur in this case. According to Lutembacher (1936) the murmur arises where a small vein enters a dilated one, for example at the junctions of the para-umbilical veins with the dilated and tortuous epigastric veins. The disappearance of the sound on light pressure over the epigastrium would be compatible with this explanation. On the other hand the maximum intensity of the bruit in the region of the xiphisternum suggests that it may originate in turbulence occurring at the junction of the left portal and umbilical veins. The disappearance of the sound on pressure over the epigastrium could then be accounted for by the cessation of flow into the patent end of the umbilical vein. Observations made by McFadzean and Gray (1953) provide some support for this view. In five out of nine cases of hepatic cirrhosis they reported that a venous hum was not audible over the epigastrium but was detected on direct auscultation of the liver and became progressively louder as the porta hepatis was approached. Large veins were demonstrated in the falciform ligament in three of these cases. In another case which they reported in detail they concluded that the murmur originated in arteriovenous communications within the liver and was conveyed directly to the abdominal wall. That this was not the mechanism of its production in the present case is suggested by the fact that the murmur disappeared when light pressure was applied to the epigastrium.

\section{Summary}

A case of hepatic cirrhosis and portal hypertension in which a bruit could be heard in the epigastrium is described. The phonocardiogram made during life is presented together with a drawing of the anastomosis made at necropsy. A venogram was also made after death.

\section{REFERENCES}

Armstrong, E. L., Adams, W. L., Tragerman, L. J., and Townsend, E. W. (1942). Ann. intern. Med., 16, 113. Baumgarten, P. von (1908). Arb.a.d. Geb. Path. Anat. Bakt., 6, 93.

Bloom, H. J. G. (1950). Brit. Heart J., 12, 343.

Burow, K. A. von (1838). Quoted by Butler, H.

Butler, H. (1952). Thorax, 7, 159.

Cruveilhier, J. (1835). Anatomie Pathologique du Corps Humain. Vol. I, Paris.

Hanganutz, M. (1922). Pr. Med., 30, 732.

Laennec, R. T. H. (1819). De l'Auscultation Médiate, ou Traité du Diagnostic des Maladies des Poumons et du Caur, fondé principalement sur ce nouveau moyen d'exploration. Paris.

Lutembacher, R. (1936). Pr. Med., 44, 847.

McFadzean, A. J. S., and Gray, J. (1953). Lancet, 2, 1128.

McNee, Sir John, and Macpherson, A. I. S. (1952). Brit. Encyclopadia of Medical Practice, 2nd ed., Vol. XI, p. 459 . Butterworth: London.

Pégot (1833). Bull. Soc. Anat., Paris, 8, 49. Quoted by Armstrong et al.

Sappey, M. C. (1889). J. de L'Anat., 19 N.S., 517.

Segall, H. N. (1923). Surg. Gynec. Obstet., 37, 152. 